\title{
Research Article \\ Effects of Absorber Emissivity on Thermal Performance of a Solar Cavity Receiver
}

\author{
Jiabin Fang, Nan Tu, and Jinjia Wei \\ State Key Laboratory of Multiphase Flow in Power Engineering, Xian Jiaotong University, Xian 710049, China \\ Correspondence should be addressed to Jinjia Wei; jjwei@mail.xjtu.edu.cn
}

Received 14 March 2014; Accepted 8 April 2014; Published 8 May 2014

Academic Editor: Shaohua Shen

Copyright (C) 2014 Jiabin Fang et al. This is an open access article distributed under the Creative Commons Attribution License, which permits unrestricted use, distribution, and reproduction in any medium, provided the original work is properly cited.

\begin{abstract}
Solar cavity receiver is a key component to realize the light-heat conversion in tower-type solar power system. It usually has an aperture for concentrated sunlight coming in, and the heat loss is unavoidable because of this aperture. Generally, in order to improve the thermal efficiency, a layer of coating having high absorptivity for sunlight would be covered on the surface of the absorber tubes inside the cavity receiver. As a result, it is necessary to investigate the effects of the emissivity of absorber tubes on the thermal performance of the receiver. In the present work, the thermal performances of the receiver with different absorber emissivity were numerically simulated. The results showed that the thermal efficiency increases and the total heat loss decreases with increasing emissivity of absorber tubes. However, the thermal efficiency increases by only $1.6 \%$ when the emissivity of tubes varies from 0.2 to 0.8 . Therefore, the change of absorber emissivity has slight effect on the thermal performance of the receiver. The reason for variation tendency of performance curves was also carefully analyzed. It was found that the temperature reduction of the cavity walls causes the decrease of the radiative heat loss and the convective heat loss.
\end{abstract}

\section{Introduction}

Tower-type solar power generation is widely adopted in the establishment of large-scale solar thermal power plants. With more and more demonstration systems running successfully, this power generation way has attracted a lot of attention all over the world and has a tendency to be one of mainstream high power generation ways. At the same time, the thermal efficiency of the whole solar power system is more and more seriously considered because of the considerable construction cost. Higher thermal efficiency means more power will be generated in the same time, which will decrease the average cost and improve the competitiveness. Among all the components in solar power system, solar receiver is a key one, which converts solar energy into thermal energy in tower-type system. One possible configuration usually used is the cavity receiver because of its large surface area and low heat loss. Ávila-Marín [1] regarded cavity receiver as the best alternative to tube receivers, which would become advanced technology for the deployment of new solar tower power plants. For a solar cavity receiver, there is an aperture on the front face of the cavity, through which sunlight concentrated by a heliostat field projects onto the surfaces inside the receiver. Meanwhile, the existence of the aperture causes unavoidable heat loss. So the thermal efficiency and the heat loss are the important indicators for evaluating the thermal performance of a solar cavity receiver, and the study on the thermal performance also wins much attention from researchers. An analytical model of large cubical central receivers was proposed by Clausing [2], based on the assumption that two factors govern the convective heat loss: (i) the ability to transfer mass and energy across the aperture and (ii) the ability to heat air inside the cavity. The latter factor was found to be more important. This model was later refined and verified with experimental results and good agreement was found [3]. Juárez et al. [4] and Prakash et al. [5] gave a brief review on the natural convection in cavities. It revealed that many researchers have studied both experimentally and numerically the cavities with different boundary conditions in order to better understand the mechanism of heat loss. Moreover, the literature survey showed that most investigations on the heat loss of cavity are limited to the boundary conditions with isothermal and/or adiabatic surfaces. Paitoonsurikarn et al. [6] numerically investigated the natural 
convective heat loss of four different open cavity receivers and validated the results with the experimental data. They found that the numerical and the experimental results agree well with each other. A new correlation was also presented for the natural convection based on the numerical results. This correlation proposes a new concept of an ensemble cavity length scale for considering the combined effect of cavity geometry and inclination. And the correlation has high accuracy compared with other ones. Taumoefolau et al. [7] experimentally and numerically studied the relationship between the natural convective heat loss and the inclination angles of an open cavity receiver. Electrical heating was used as a heat source. It was found that the highest loss appears at $0^{\circ}$ and the loss decreases as the inclination angle approaches $90^{\circ}$. They carried out the numerical simulation on the convective heat loss of the receiver with CFD. The numerical result shows good agreement with the experimental data. Le Quere et al. [8] investigated the heat loss from an isothermal cubic cavity for Rayleigh numbers $10^{7} \leq \mathrm{Ra} \leq 10^{9}$. The total heat loss was found to be strongly dependent on the cavity inclination and correlations for each inclination were established. Reynolds et al. [9] studied the steady-state computational analysis of trapezoidal cavity receiver. Experimental and computational studies of heat loss characteristics were carried out, and flow visualization technique was used to capture the flow patterns. CFD prediction of heat loss appears to be $40 \%$ less compared with experimental results, which should be caused by the uncertainties in the experimental work. Harris and Lenz [10] analyzed the thermal performance of five different geometries of cavity receivers (cylindrical, heteroconical, conical, spherical, and elliptical) and found that the deviation in rim angle of concentrator and the cavity geometry cause great variations on power profiles inside the cavity receiver. Reddy and Kumar [11, 12] presented a numerical study of transfer in a cavity receiver. A $2 \mathrm{D}$ simulation model and a $3 \mathrm{D}$ simulation model for combined natural convection and surface radiation were successively developed. The influence of operating temperature, emissivity of the surface, orientation, and geometries on the total heat loss of the receiver was investigated. The results showed that the convective heat loss of the modified receiver is significantly influenced by the inclination of the receiver whereas the radiative heat loss is considerably affected by surface properties. They also found that the 3D model can be used for accurate estimation of heat loss. Gonzalez et al. [13] numerically investigated the natural convection and the surface thermal radiation of an open cavity receiver considering large temperature differences and variable fluid properties. The numerical result indicated that, for large temperature differences between the hot wall and the bulk fluid, the radiative heat transfer is more important than the convection. Sharma et al. $[14,15]$ and Vivek et al. [16] studied conjugate natural convection and surface radiation in rectangular enclosures, inclined differentially heated enclosures, and air-filled tilted enclosures for a wide range of the tilt angle. They found that surface radiation weakens natural convection. However, the reduction in the convection effect is compensated by the contribution of radiation. A 2D numerical analysis of combined heat transfer (transient natural convection, surface thermal radiation, and conduction) in an air-filled square enclosure was carried out by Martyushev and Sheremet [17]. It was found that the average convective Nusselt number increases with the Rayleigh number Ra and thermal conductivity ratio $k_{1,2}$, and it decreases with the surface emissivity $\varepsilon$ and the ratio of solid wall thickness to cavity spacing $L$, while the average radiative Nusselt number increases with $\mathrm{Ra}$ and $k_{1,2}$, and it decreases with $l / L$. Wu et al. [18] conducted an experimental investigation using electrically heating method to explore the effects of surface boundary condition, tilt angle, and heat flux on heat loss of a fully open cylindrical cavity. It was concluded that temperatures of bottom surface fluctuate in a small region, and side surface temperatures decrease with increasing position departure from bottom surface. The natural convection heat loss is sensitive to the tilt angle in comparison with the radiation and conduction heat losses. In addition, the empirical correlations of the natural convection, radiation, and total heat loss Nusselt numbers versus the Grashof number, tilt angle, and ambient temperature were proposed. Hogan et al. [19] presented a numerical model for an axisymmetric solar cavity receiver. The results showed that the model is better for small-to-midsized apertures than for large ones. Both the total solar energy rate and the convective heat loss significantly affect the thermal performance of the receiver. And the distribution of input solar flux affects the temperature distribution a lot inside the receiver. $\mathrm{Li}$ et al. [20] established an easy-to-use global steady-state model for a cavity receiver. Each part of heat loss can be easily calculated by using this model. The elements, which influence the receiver thermal performance, including receiver area, surface emissivity, reflectivity, absorber tube number, and tube diameter, were all taken into account. They found that the receiver surface emissivity has little influence on the receiver efficiency. However, the surface reflectivity has strong influence on the receiver thermal performance. And low surface reflectivity can obtain high thermal performance of the receiver. Zhang et al. [21] proposed a transfer function method for testing the dynamic performance of a cavity receiver. They adopted this method to predict the outlet temperatures and compared the predicted results with the indoor transient experimental data. The result showed that the transfer function method can accurately predict the outlet temperature trends despite the fact that some errors exist between the predicted and the measured outlet temperatures. They also analyzed the fact that the errors may have originated from the changing flow rate. Baker et al. [22] introduced CESA-1 cavity receiver, which is a demonstration power station in Spain. In their report, receiver controls, locations based on analogic measurements, cold and warm receiver start-ups, and transient response to cloud-induced changes were mentioned when CESA-1 was in operation. In order to minimize start-up time, the appropriate operating strategies were implemented during CESA-1 receiver start-up. Fang et al. [23] proposed a combined calculation method for evaluating the thermal performance of the solar cavity receiver. With this method, the thermal performance of a solar cavity receiver, a saturated steam receiver, is simulated under different wind environments. The results indicated that changing the wind angle or velocity can obviously affect 
the thermal performance of the receiver. And the heat loss reaches maximum under side-on wind condition. Based on this numerical model, the same authors [24] established a new model for calculating the thermal performance of the solar cavity receiver during start-up processes. The solar energy required by the aperture of the receiver was also obtained during start-up. The results showed that the thermal efficiency appears very low but sharply increases in the early stage of start-up. The convective heat loss is the main heat loss even at the end of start-up processes. Yu et al. [25] presented two models, respectively, for the collector and cavity receiver. The two models were coupled together to simulate and design the solar power system. They [26] also proposed an integrated receiver model for full range operation conditions in order to simulate and evaluate the dynamic characteristics of a solar cavity receiver. Based on this model, the dynamic characteristics of the solar cavity receiver were tested and also they calculated the thermal loss with different wind conditions. Montes et al. [27] analyzed a new optimized heat transfer model in the absorber surface of a thermofluid dynamic design of a solar central receiver. The fluid flow scheme designed can present lower temperature difference between side tubes in the same pass and higher uniform outlet temperature of all circuits. As we know, when sunlight passes through the atmosphere, solar radiation is weakened due to the absorption of the gas. The extinction effect of the ozone on ultraviolet lights is particularly strong, while vapor and $\mathrm{CO}_{2}$ mainly absorb infrared lights. Therefore, for solar radiation reaching the earth's surface, about $95 \%$ of the energy is concentrated in the wavelength range of $0.2-2 \mu \mathrm{m}$ [28]. However, for infrared energy radiated by the cavity receiver, the energy proportion reaches up to $99 \%$ in the wavelength range larger than $2 \mu \mathrm{m}$, because the wall temperature of cavity receiver is only about hundreds of degrees. Thus the absorption of the receiver for sunlight (0.2$2 \mu \mathrm{m})$ on the earth surface and infrared light (larger than $2 \mu \mathrm{m}$ ) radiated by cavity walls is distinguished in the present study. In Kesselring's [29] book, the absorber tubes inside a cavity receiver would usually be covered with a layer of coating having high absorptivity for sunlight. The purpose of taking this measure is to improve the thermal efficiency of the receiver. However, to the best knowledge of the authors, there are few investigations about the influence of absorber emissivity on thermal efficiency of the receiver. In the present work, some numerical studies were carried out to investigate the performance of cavity receiver with the same absorptivity for sunlight but different absorptivity for infrared light. Obviously, the lights emitted by absorber surfaces are almost infrared lights as the temperature is not too high. Therefore, the emissivity of absorber is almost equivalent to the absorptivity for infrared light. The thermal performances of receiver with different emissivity were obtained, and the reasons for variation tendency of performance curves were carefully analyzed. The technology for varying the emissivity (absorptivity for infrared light) of absorber while keeping its absorptivity for sunlight unchanged can be achieved by plating nanoparticles. When nanoparticles are plated on the surface of absorber, the absorption for sunlight and infrared light can be changed. And different materials and diameters of nanoparticles can also vary the absorption for different wavelengths of the absorber.

\section{Computational Model}

A combined computational model was employed for calculating the thermal performance of the solar cavity receiver shown in Figure 1, which was proposed by Fang et al. [23]. This model includes three aspects: the calculation for the radiative heat transfer inside the receiver, the selection of the flow boiling heat transfer correlations inside the absorber tubes, and the calculation for the air flow field around the receiver. The thermal efficiency and the heat loss of the receiver are finally obtained by coupling these three aspects with an iterative scheme.

\subsection{Calculation for the Radiative Heat Transfer inside the} Receiver. The Monte Carlo ray tracing method (MCRT) is used to calculate the radiative heat transfer inside the receiver, which can well adapt to all kinds of complex geometries. MCRT is a random simulation method based on probability statistics. Its basic thought on radiation is that the radiative heat transfer process falls into a series of subprocesses: emission, reflection, absorption, scattering, and escape. Every subprocess has an occurrence probability and is determined by random numbers. It has been considered that every light ray carries no energy, so the MCRT method is separated into two parts: the Monte Carlo simulation and the thermal simulation. This treatment can calculate large-scale light rays and obtain high precision results. The object is divided into many surface units and volume units. Let every unit emit a certain quantity of light rays and every light ray is traced and judged by considering whether it is absorbed, scattered, or reflected by surface or volume units or it escapes from the system. Therefore, the number of light rays that every unit finally gains is counted and the radiative heat transfer factor can be computed. The Monte Carlo simulation part is just for calculating the radiative heat transfer factor $\mathrm{RD}_{i j}$. It is defined as the ratio of the number of light rays unit $j$ gains from unit $i$ to the number of light rays emitted by unit $i$. The object studied in the present work is a solar cavity receiver shown in Figure 1. Since there is only air inside the receiver and the air almost exerts no radiation, the scattering can be omitted in the radiative heat transfer process and there are no volume units in the system. Therefore, the computational model of the Monte Carlo simulation only includes the emitting location and direction model and the absorptionreflection model. The emitting location and direction model was introduced in detail in the reference by Fang et al. [23]. When a light ray projects onto a surface unit, it would be reflected or absorbed by this unit. At this time, a random number $R_{\alpha}$ isused to judge whether it is absorbed or not. The absorption-reflection probability model is as below. For sunlight, if $R_{\alpha} \leq \alpha_{\text {sun }}$, it is absorbed by the unit which it reaches. Similarly, for infrared light, if $R_{\alpha} \leq \alpha_{\text {infrared }}$, the light ray is also absorbed. Oppositely, if $R_{\alpha}>\alpha_{\text {sun }}$ or $R_{\alpha}>\alpha_{\text {infrared }}$, the light ray is reflected. Here, $\alpha_{\text {sun }}$ and $\alpha_{\text {infrared }}$, respectively, represent the absorptivity of the surface unit for sunlight and for infrared light. If the light ray is absorbed by the unit, 

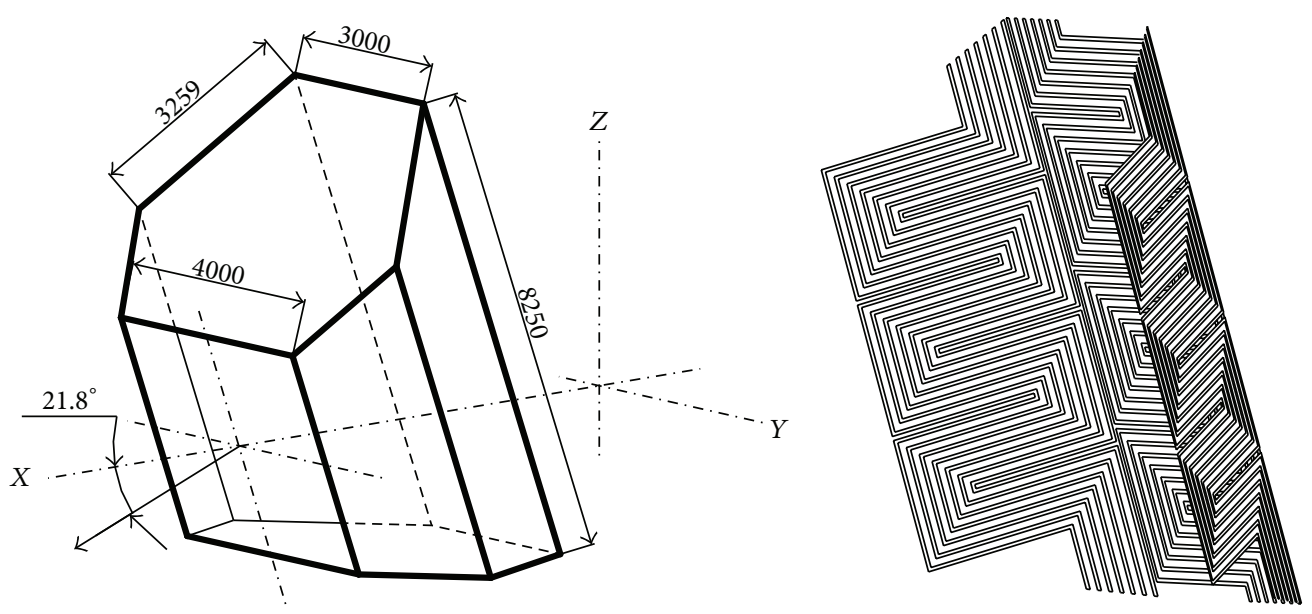

FIgURE 1: Cavity geometry and absorber tubes layout.

the number of light rays absorbed by this unit should increase by one. And if it is reflected, the emitting direction model should be used again to figure out the direction of the reflection. Tracing a number of light rays can obtain the stable statistical results. After the radiative heat transfer factor has been gained, the thermal simulation part can be conducted. It is for calculating the heat flux and the temperature of surface units by solving the energy equations as follows, where $Q_{c \text {,loss }}$ represents the convective heat loss and $Q_{t}$ is the energy transferred inside to the working fluid from the absorber tubes:

$$
\begin{array}{r}
\varepsilon_{i} S_{i} \sigma T_{i}^{4}+Q_{c, \text { loss }, i}+Q_{t, i}=\sum_{k=1}^{N} \varepsilon_{k} S_{k} \sigma T_{k}^{4} \mathrm{RD}_{k i} \\
(i=1, N) .
\end{array}
$$

If the light rays escape from the receiver through the aperture, it is considered as the heat loss. Using the MCRT method can also obtain the reflective heat loss and the radiative heat loss. The reflective heat loss means the solar energy escapes from the receiver after once or several times reflections, while the radiative heat loss means the infrared energy radiated by cavity walls and absorber tubes ultimately projects to the aperture and escapes. If the geometry of the receiver and the computational model of the Monte Carlo simulation keep unchanged, the radiative heat transfer factor will only need to be calculated once before the iterative calculation. But the thermal simulation part should be done every time. In order to study how the emissivity of the absorber tubes affects the thermal performance of the solar cavity receiver, the emissivity is different in every calculation case. Once the emissivity varies, the radiative heat transfer factor needs to be recalculated again.

\subsection{Selection of the Flow Boiling Heat Transfer Correlations.} Subcooled water delivered by a circulating pump to the absorber tubes is heated into saturated water and steam. The flow during this phase transition process is divided into three regions: single-phase flow region, subcooled boiling flow region, and saturated boiling flow region. Among them the subcooled boiling flow region should be subdivided according to the mechanism of heat transfer, namely, partial boiling flow region, fully developed boiling flow region, and significant void flow region. Appropriate heat transfer correlations proposed by Kandlikar [30] and identification criteria by Hsu [31] are selected for each region to calculate the convective heat transfer inside the tubes. As long as the inlet conditions of absorber tubes and the heat flux transferred into working fluid are known, the convective heat transfer coefficients and the wall temperature of absorber tubes can be calculated by using selected correlations.

\subsection{Calculation for the Air Flow Field around the Receiver.} As the solar cavity receiver is usually laid at $60-100 \mathrm{~m}$ high on top of the solar tower, the air around it is in a turbulent state. So the convective heat loss between the receiver and the air is another form of heat loss besides the reflective and the radiative heat loss. The commercial software FLUENT is chosen to calculate the convective heat transfer. The standard $k-\varepsilon$ turbulent model is selected, because it is widely used for general turbulent flow. And the SIMPLE algorithm is employed. The outer walls of the receiver are considered adiabatic and the no-slip velocity boundary condition is adopted. The side-on wind is chosen as the far field boundary condition, because it is the most rigorous wind condition than other directions, which causes the greatest convective heat loss according to Fang et al. [23]. The wind speed at a height of $10 \mathrm{~m}$ is considered to be the reference speed, and the speeds at different heights can be obtained by the following power law expression proposed by Sutton [32]:

$$
v=v_{10 \mathrm{~m}}\left(\frac{h}{10}\right)^{1 / 7}
$$

As long as the conditions of air flow in the far field and the wall temperature of the cavity and the absorber tubes are known, the convective heat loss between the receiver and the air can be calculated. 


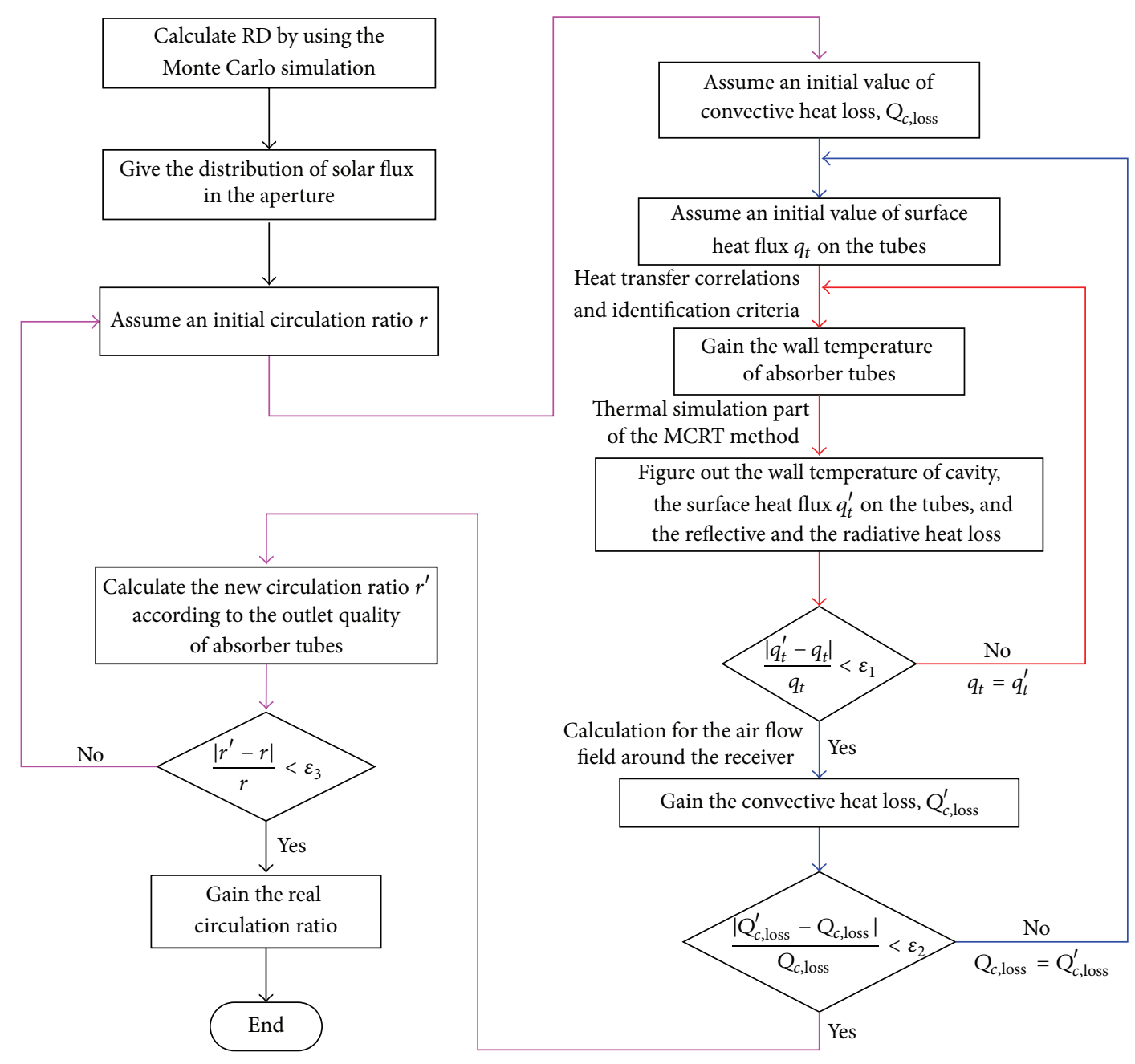

FIGURE 2: Flow chart for calculating the thermal performance of the solar cavity receiver.

2.4. Iterative Solution Procedure. A problem should be noticed that the parameters required for calculating the three aspects above are interrelated and no aspect can be solved alone. When calculating the heat flux on the surface of absorber tubes with the MCRT method, the wall temperature of absorber tubes and the convective heat loss are needed and involved in the energy equations. When calculating the wall temperature of absorber tubes, the heat flux transferred from the tubes into the working fluid must be known. Besides, when calculating the convective heat loss between the receiver and the air, the wall temperature of the cavity and the absorber tubes is needed as the boundary condition. So in order to figure out all the parameters, an iterative scheme is required by coupling these three aspects.

Figure 2 shows the flow chart for calculating the thermal performance of the solar cavity receiver. At first, the radiative heat transfer factor should be calculated with the Monte Carlo simulation before the iteration. Since the radiative heat transfer takes place between any two surface units, the calculation of radiative heat transfer factor is a timeconsuming task. Therefore, a proper number of light rays emitted by every unit are vital in order to ensure the least time of calculation and the accuracy of results. Under the condition that the distribution of solar flux in the aperture is given, the whole iterative procedure consists of three loops for the thermal performance calculation. The inner loop is for calculating the wall temperature of the cavity and the absorber tubes, the heat flux on the surface of tubes, and the reflective and the radiative heat loss. The second loop is for calculating the convective heat loss between the receiver and the air with FLUENT. And the outer loop is used to figure out the circulation ratio. It means the ratio of the total recirculated mass flow rate in the absorber tubes to the mass flow rate of saturated steam generated, which can be calculated according to the outlet quality.

\section{Results and Discussion}

A solar cavity receiver with the similar geometry to CESA1 receiver [22] was adopted in the present work for studying the influence of surface emissivity. The cavity is a prism with inclined top and bottom faces, which is shown in Figure 1. The back wall of the cavity is $8.25 \mathrm{~m}$ in height and $3 \mathrm{~m}$ in width. The width of the two side walls adjacent to 


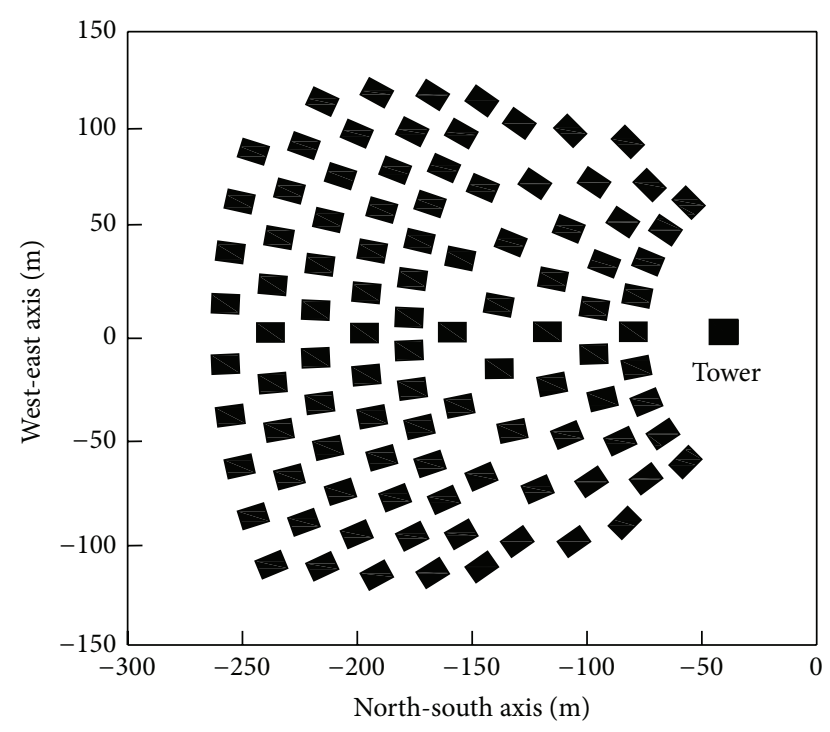

FIGURE 3: Layout of heliostat field.

the back wall is also $3 \mathrm{~m}$, while the other two side walls near the aperture are $2 \mathrm{~m}$ in width. There is only one aperture of $4 \mathrm{~m} \times 4 \mathrm{~m}$ on the front surface of the receiver. There are three panels of absorber tubes, the layout of which can be found in Figure 1, installed inside the cavity. According to Baker's description referring to CESA-1 [22], the three back walls inside the cavity gain much more heat flux than other walls. Therefore, the absorber tubes are arranged in front of these walls and cover the back walls as much as possible. Every panel is formed of a series of stainless steel serpentine tubes, and the gap between every two tubes is filled with flat steel. This kind of design can make the absorber tubes get more energy and protect the back walls against direct irradiation. The central panel has 7 passes and 20 tubes/pass, while the each side one, respectively, has 6 passes. The receiver was assumed to be laid at a height of $100 \mathrm{~m}$. And it has a downward inclination of $21.8^{\circ}$ in order to gain the most solar energy from heliostats. Several boundary conditions should be given before calculating the thermal performance of the solar cavity receiver. The layout of the heliostat field designed by Wang and Wei [33] was employed to obtain the irradiation situation in the aperture. Figure 3 shows the layout of heliostat field. There are 100 sets of parabolic mirrors with a square border of $10 \mathrm{~m} \times 10 \mathrm{~m}$ in the heliostat field. The solar tower in front of the heliostat field is about $120 \mathrm{~m}$ in height. Figure 4 shows the distribution of solar flux in the aperture, which was considered as the inlet boundary condition in the thermal simulation part of MCRT method. The distribution appears to be highly nonuniform. The center of the aperture gets the highest solar flux, and at the boundary much lower solar flux is concentrated. These data were obtained from the Institute of Optics and Fine Mechanics and Physics, Chinese Academy of Sciences, which were calculated according to the layout of the heliostat field mentioned above. The reflected sunlight irradiates to the aperture of the cavity within a certain range of angle due to the fan pattern of heliostats. And Figure 5

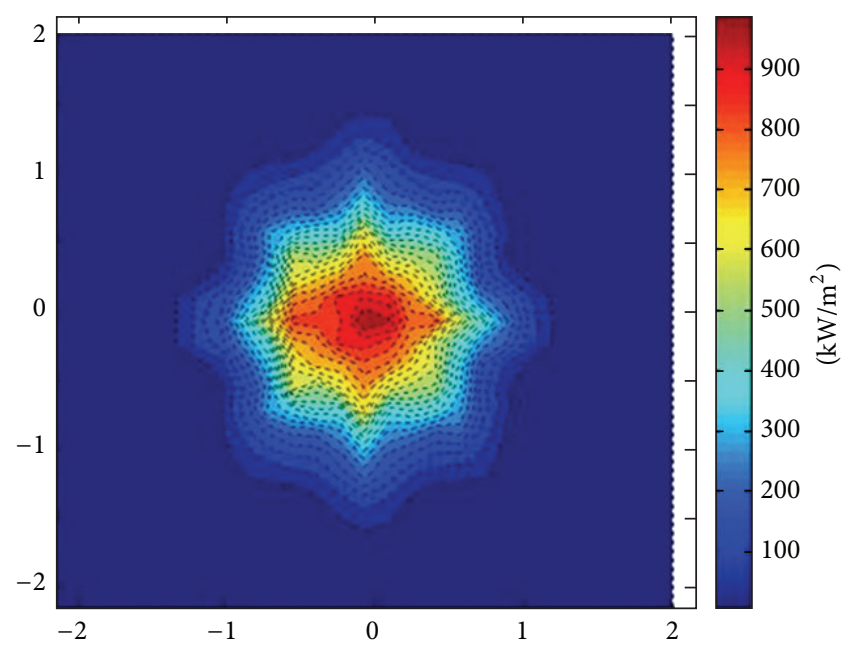

FIGURE 4: Distribution of solar flux in the aperture.

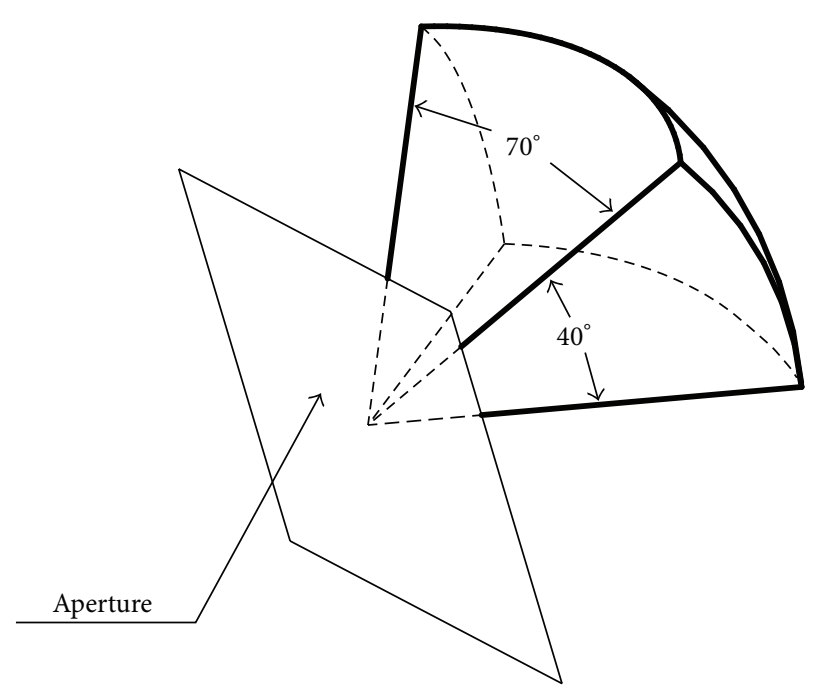

FIGURE 5: Range of solar irradiation angles.

shows the range of irradiation angles. It is $70^{\circ}$ in left-toright direction, with each side $35^{\circ}$, while it is $40^{\circ}$ in top-tobottom direction, with $30^{\circ}$ upward and $10^{\circ}$ downward. Solar irradiation angles were regarded as the emitting directions of rays in the aperture when the Monte Carlo simulation part was conducted. The wind speed at $10 \mathrm{~m}$ high above ground was assumed to be $6 \mathrm{~m} / \mathrm{s}$. So the wind speed around the receiver can be calculated by the expression (2). The sketch map of the side-on wind is shown in Figure 6. And the wind flows horizontally from the right side of the receiver. When the aperture of the cavity acquires as much solar flux as shown in Figure 4, the receiver operates under the steady-state, and the rated working pressure is $7 \mathrm{MPa}$. All the absorber tubes have the same inlet temperature. The circulating mass flow rate is $70 \mathrm{t} / \mathrm{h}$ for the central panel, while it is $35 \mathrm{t} / \mathrm{h}$ for each side one.

The focus of this paper is to study the effects of emissivity of the absorber tubes on the thermal performance of the solar 


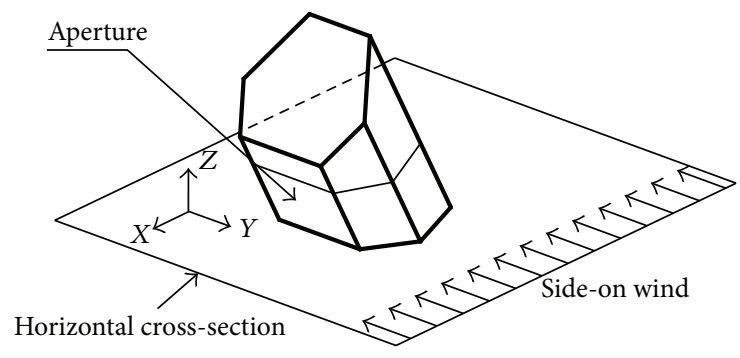

Figure 6: Sketch map of side-on wind.

TABLE 1: Emissivity and absorptivity of the materials inside the receiver.

\begin{tabular}{lccc}
\hline Materials & Emissivity & $\begin{array}{c}\text { Absorptivity } \\
\text { for sunlight }\end{array}$ & $\begin{array}{c}\text { Absorptivity } \\
\text { for infrared } \\
\text { light }\end{array}$ \\
\hline $\begin{array}{l}\text { Firebrick } \\
\text { (cavity walls) }\end{array}$ & 0.9 & 0.9 & 0.9 \\
$\begin{array}{l}\text { Stainless steel tube } \\
\text { (absorber tubes) }\end{array}$ & $0.2,0.4,0.6,0.8$ & 0.8 & $0.2,0.4,0.6,0.8$ \\
\hline
\end{tabular}

cavity receiver. Table 1 lists the emissivity and the absorptivity of the materials inside the receiver. Among them, the material of the cavity walls is firebrick, and it is usually dark color. Therefore, the emissivity and the absorptivity of the cavity walls are both quite high, and they were set to be 0.9 . Because the absorber tubes should obtain solar energy as much as possible, the absorptivity for sunlight is also high and the value is 0.8 . In the present study, the emissivity of the absorber tubes is the key research variable. It, respectively, increases from 0.2 to 0.8 . It should be noticed that the absorptivity for infrared light is equal to the emissivity of the materials, which can be observed from Table 1. According to Kirchhoff's law [28], for a diffuse gray body, the absorptivity is equal to the emissivity at the same temperature, which means $\alpha(T)=\varepsilon(T)$. When the receiver works in normal conditions, the temperature of cavity walls is $300-500^{\circ} \mathrm{C}$ and the outer wall of absorber tubes has the temperature of $300-400^{\circ} \mathrm{C}$. The absorptivity for infrared light will not change obviously within the temperature difference of $200^{\circ} \mathrm{C}$. Besides, the walls and tubes will emit infrared light mostly as the temperature is not very high. Therefore, both for the cavity walls and the absorber tubes, the absorptivity for infrared light was considered to be the same as the emissivity. When calculating the thermal performance of the solar cavity receiver with the increase of the emissivity, the absorptivity for infrared light varies accordingly.

Figures 7 and 8 illustrate the change trends of thermal efficiency and heat loss of the receiver when the emissivity of the absorber tubes varies from 0.2 to 0.8 . The results show that the thermal efficiency increases and the total heat loss decreases with increasing emissivity. The infrared radiative heat transfer exists between the absorber tubes and the cavity walls inside the receiver. And the temperature of cavity walls is usually higher than the absorber tubes. When the emissivity (absorptivity for infrared light) of tubes increases, more infrared energy radiated from cavity walls is obtained by the absorber tubes. That is the reason for the rising thermal efficiency with increasing emissivity. Compared with the external receiver, which is another type of receivers utilized in tower-type solar power system, these results are not applicable. Because the absorber tubes are exposed to the air in the external receiver, the radiative heat loss will rise when the emissivity of tubes increases. However, it can be noticed that, in Figure 7, the increase of thermal efficiency is only about $1.6 \%$ although the emissivity increases from 0.2 to 0.8 . The absolute value of total heat loss only decreases by about $83.5 \mathrm{~kW}$. It indicates that the change of the emissivity of the absorber tubes has small effects on the thermal efficiency of the receiver. The total heat loss is the sum of reflective heat loss, radiative heat loss, and convective heat loss. The trends of three kinds of heat loss are, respectively, shown in Figure 8. Since the absorptivity for sunlight is unchanged in four different cases, the behaviors of sunlight, which is absorbed or reflected by the units inside the receiver, are all the same. It causes the reflective heat loss unchanged with the increase of the emissivity. The radiative heat loss decreases from $227 \mathrm{~kW}$ to $167 \mathrm{~kW}$, reducing by about $26.4 \%$, as can be seen from Figure 8 . The radiative heat loss comes from the infrared energy radiated by absorber tubes and cavity walls escaping through the aperture. The average wall temperature of absorber tubes is plotted in Figure 9. It can be found that the wall temperature of three panels varies a little and slightly increases with increasing emissivity. It can be explained as below. The emissivity of tubes increases, which will make heat loss of the receiver and radiation of tubes larger, but the energy obtained by the tubes will not decrease. Because the tubes are inside the cavity, they can obtain the infrared energy from cavity walls, which usually have higher temperature. It should be noticed that the absorptivity of tubes for infrared light is equal to the emissivity. So the higher the emissivity of tubes is, the more energy the tubes will get from cavity walls. Figure 10 shows the distributions of temperature of cavity walls. As the absorptivity of tubes for infrared light increases, the absorber tubes gain more infrared energy from the cavity walls. So the temperature of cavity walls decreases with increasing emissivity. The reduction of wall temperature of the cavity is the major reason for the decrease of the radiative heat loss. The convective heat loss is the main form of heat loss, as can be seen in Figure 8, which is more than twice as much as the reflective heat loss and the radiative heat loss. It also decreases a little when the emissivity increases from 0.2 to 0.8 , because the temperature of cavity walls is reduced. It can also be observed from Figure 10 that the top face gets the most heat flux and has the highest temperature than other walls, which is determined by the limit of solar irradiation angles. From Figure 5, it can be deduced that the upper part of the middle panel, which covers the back walls of the cavity, will receive the most sunlight. So the top face, nearest to this part, will obtain the most reflected sunlight. Since the right side-on wind is selected in the present study, the air inside the receiver swirls from the left side wall to the right side wall. Thus, the air temperature near the right side wall would be higher than that near the left side wall due to heat transfer along the air flow path. So the temperature of the left wall is relatively lower than the right one. As the absorber 


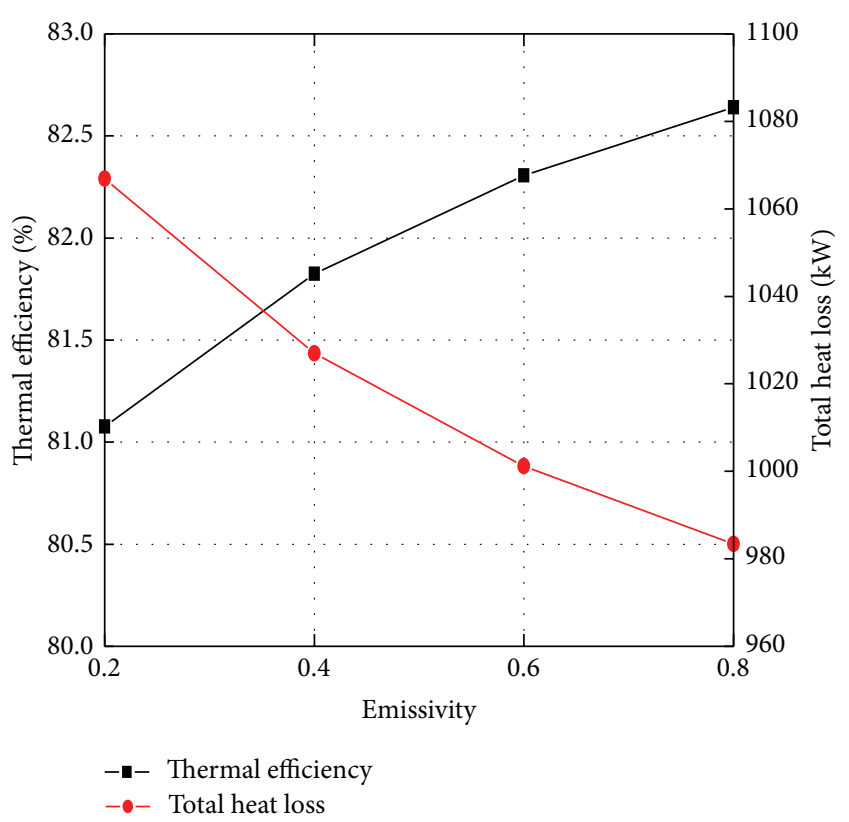

FIgURE 7: Thermal efficiency and total heat loss of the receiver.

tubes are laid in front of the three back walls and they block most of radiative energy, the temperatures of the three back walls are the lowest. But some areas which are not covered by the panels have the higher temperature. The distribution of heat flux on the absorber panels was figured out and shown in Figure 11. When the emissivity of absorber tubes varies from 0.2 to 0.8 , the distributions of heat flux are almost the same and increase slightly. The solar cavity receiver usually has only one aperture; thus the sunlight projects onto the surfaces inside the receiver only from one side. And the distribution of input solar flux itself is nonuniform in the aperture. Due to the two reasons mentioned above, the distribution of heat flux on the absorber panels appears highly nonuniform, as can be found from Figure 11. The middle part of each panel gets larger heat fluxes, and the largest value is about $250 \mathrm{~kW} / \mathrm{m}^{2}$ appearing in the middle of the central panel. About $50.5 \%$ of the energy is gained by the central panel, $24.9 \%$ by the right side one, and $24.6 \%$ by the left side one. The data calculated in the present study are in good agreement with the results from Baker et al. [22] and Fang et al. [23], which also showed that about half of the energy is absorbed by the central panel and a quarter by each side one. The heat flux can directly affect the outer wall temperature of the absorber panels. As the emissivity of tubes increases, the distributions of outer wall temperature of three panels also vary a little and are much like that shown in Figure 12. The highest temperature, about $365^{\circ} \mathrm{C}$, also appears in the middle of the central panel, which is about $80^{\circ} \mathrm{C}$ higher than the saturated temperature $\left(285^{\circ} \mathrm{C}\right.$ at $7 \mathrm{MPa}$ ).

\section{Conclusions}

The numerical study on the thermal performance of a saturated water/steam solar cavity receiver with different

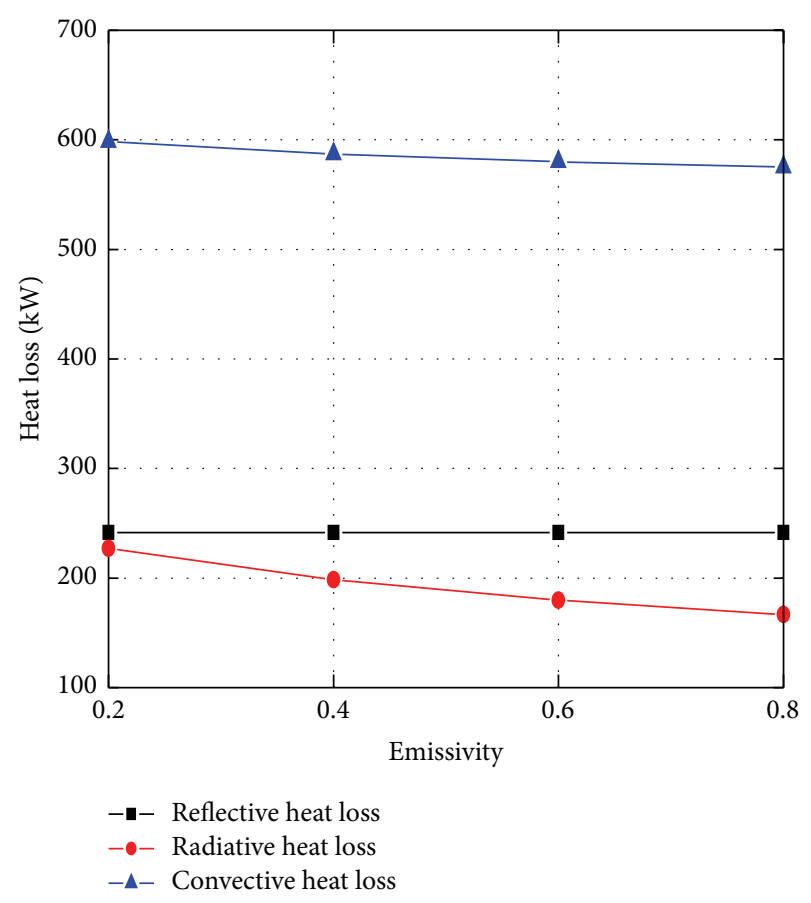

FIGURE 8: Three kinds of heat loss of the receiver.

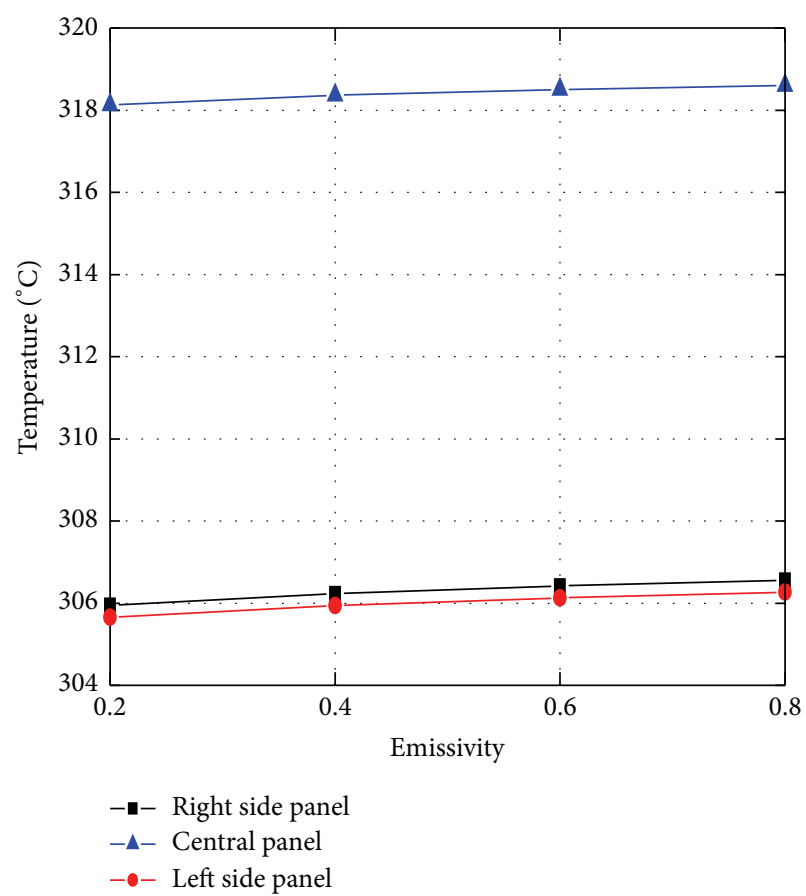

Figure 9: Average wall temperature of absorber tubes.

absorber emissivity was simulated in the present work. The results showed that the thermal efficiency increases and the total heat loss decreases with increasing emissivity of the absorber tubes. But the increase of the thermal efficiency is only about $1.6 \%$ when the emissivity varies from 0.2 to 0.8 . The change of absorber emissivity has slight effect on the thermal performance of the receiver. Therefore, in order to 

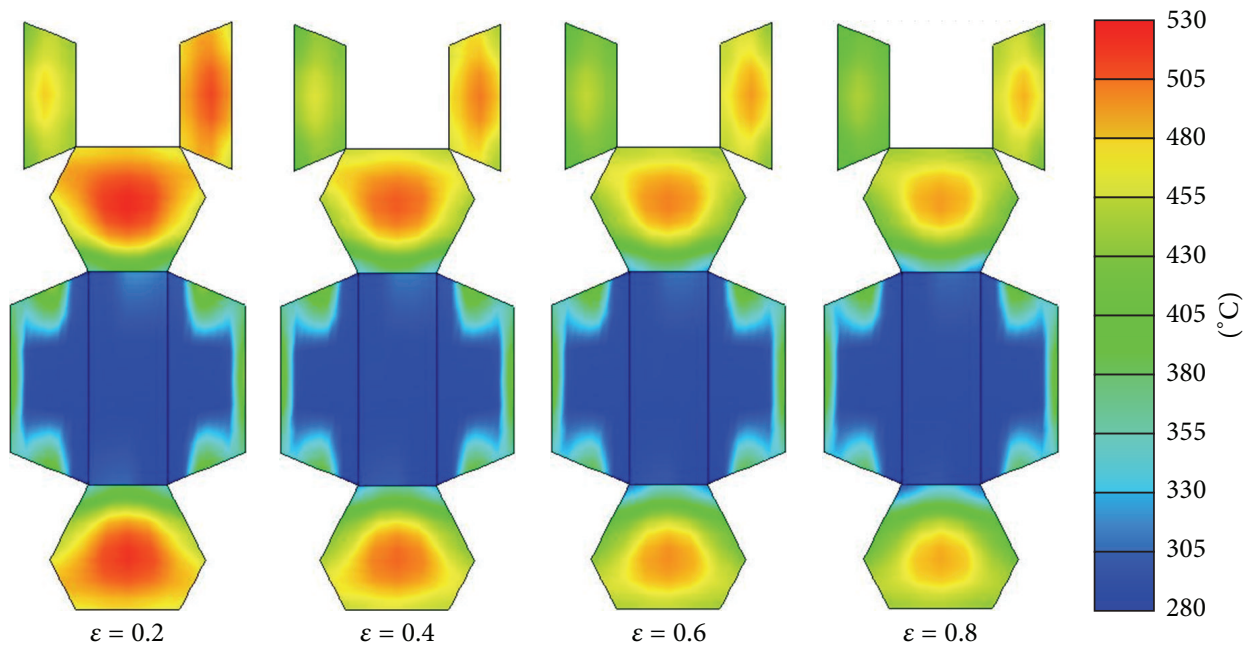

FIGURE 10: Distributions of temperature of cavity walls.

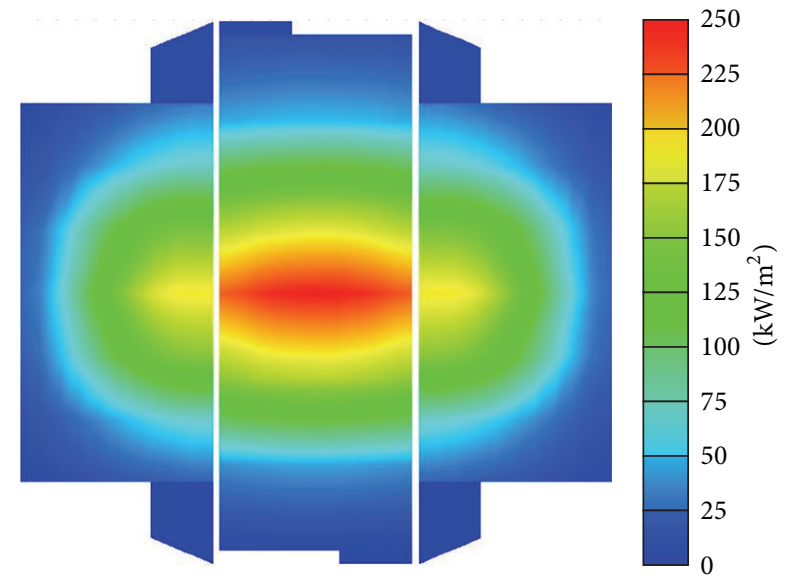

FIgURE 11: Distribution of heat flux on the absorber panels.

absorb more solar energy to achieve high thermal efficiency, the layer of coating covered on the surface of absorber tubes should have absorptivity for sunlight as high as possible, but its emissivity is not an important factor. In addition, the reason for the decrease of total heat loss was also carefully analyzed. It was found that the temperature reduction of the cavity walls causes the decrease of radiative and convective heat losses.

\section{Nomenclature}

$\mathrm{RD}$ : Radiative heat transfer factor

$R_{\alpha}$ : Random number

Q: Energy, W

T: $\quad$ Temperature, $\mathrm{K}$

S: $\quad$ Area, $\mathrm{m}^{2}$

$v: \quad$ Velocity, $\mathrm{m} / \mathrm{s}$

$h$ : Height, $\mathrm{m}$.

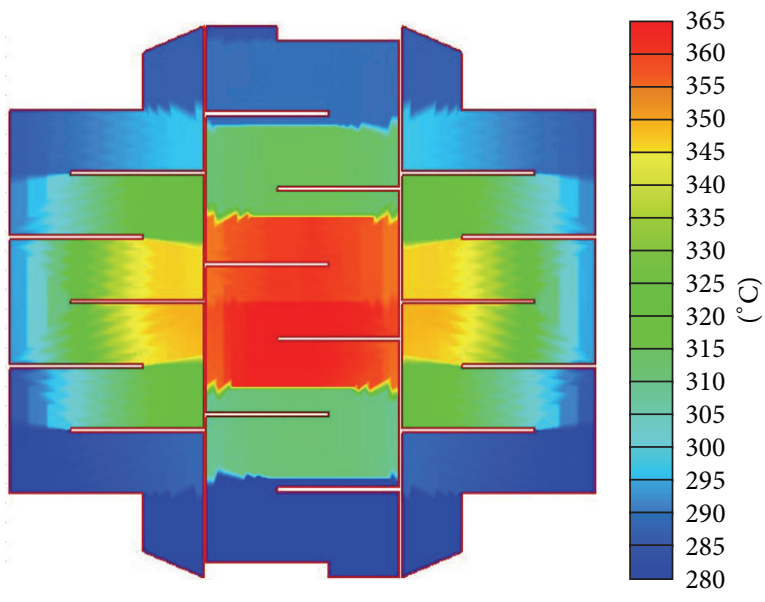

Figure 12: Distribution of outer wall temperature of the absorber panels.

\section{Greek Symbols}

$\alpha$ : Absorptivity

$\sigma$ : Stefan-Boltzmann constant, $\mathrm{W} / \mathrm{m}^{2} \mathrm{~K}^{4}$

$\varepsilon$ : Emissivity.

\section{Conflict of Interests}

The authors (Jiabin Fang, Nan Tu, and Jinjia Wei) declare that there is no conflict of interests regarding this paper.

\section{Acknowledgments}

The present work is supported by the National Basic Research Program of China (no. 2010CB227102) and the Specialized Research Fund for the Doctoral Program of Higher Education of China (no. 20130201110043). 


\section{References}

[1] A. L. Ávila-Marín, "Volumetric receivers in solar thermal power plants with central receiver system technology: a review," Solar Energy, vol. 85, no. 5, pp. 891-910, 2011.

[2] A. M. Clausing, "An analysis of convective losses from cavity solar central receivers," Solar Energy, vol. 27, no. 4, pp. 295-300, 1981.

[3] A. M. Clausing, "Convective losses from cavity solar receiverscomparisons between analytical predictions and experimental results," Journal of Solar Energy Engineering, vol. 105, no. 1, pp. 29-33, 1983.

[4] J. O. Juárez, J. F. Hinojosa, J. P. Xamán, and M. P. Tello, "Numerical study of natural convection in an open cavity considering temperature-dependent fluid properties," International Journal of Thermal Sciences, vol. 50, no. 11, pp. 2184-2197, 2011.

[5] M. Prakash, S. B. Kedare, and J. K. Nayak, "Numerical study of natural convection loss from open cavities," International Journal of Thermal Sciences, vol. 51, no. 1, pp. 23-30, 2012.

[6] S. Paitoonsurikarn, K. Lovegrove, G. Hughes, and J. Pye, "Numerical investigation of natural convection loss from cavity receivers in solar dish applications," Journal of Solar Energy Engineering, vol. 133, no. 2, Article ID 021004, 10 pages, 2011.

[7] T. Taumoefolau, S. Paitoonsurikarn, G. Hughes, and K. Lovegrove, "Experimental investigation of natural convection heat loss from a model solar concentrator cavity receiver," Journal of Solar Energy Engineering, vol. 126, no. 2, pp. 801-807, 2004.

[8] P. le Quere, F. Penot, and M. Mirenayat, "Experimental study of heat loss through natural convection from an isothermal cubic open cavity," Sandia Laboratory Report SAND81-8014, 1981.

[9] D. J. Reynolds, M. J. Jance, M. Behnia, and G. L. Morrison, "An experimental and computational study of the heat loss characteristics of a trapezoidal cavity absorber," Solar Energy, vol. 76, no. 1-3, pp. 229-234, 2004.

[10] J. A. Harris and T. G. Lenz, "Thermal performance of solar concentrator/cavity receiver systems," Solar Energy, vol. 34, no. 2, pp. 135-142, 1985.

[11] K. S. Reddy and N. S. Kumar, "Combined laminar natural convection and surface radiation heat transfer in a modified cavity receiver of solar parabolic dish," International Journal of Thermal Sciences, vol. 47, no. 12, pp. 1647-1657, 2008.

[12] K. S. Reddy and N. S. Kumar, "An improved model for natural convection heat loss from modified cavity receiver of solar dish concentrator," Solar Energy, vol. 83, no. 10, pp. 1884-1892, 2009.

[13] M. M. Gonzalez, J. H. Palafox, and C. A. Estrada, "Numerical study of heat transfer by natural convection and surface thermal radiation in an open cavity receiver," Solar Energy, vol. 86, no. 4, pp. 1118-1128, 2012.

[14] A. K. Sharma, K. Velusamy, C. Balaji, and S. P. Venkateshan, "Conjugate turbulent natural convection with surface radiation in air filled rectangular enclosures," International Journal of Heat and Mass Transfer, vol. 50, no. 3-4, pp. 625-639, 2007.

[15] A. K. Sharma, K. Velusamy, and C. Balaji, "Interaction of turbulent natural convection and surface thermal radiation in inclined square enclosures," Heat and Mass Transfer, vol. 44, no. 10, pp. 1153-1170, 2008.

[16] V. Vivek, A. K. Sharma, and C. Balaji, "Interaction effects between laminar natural convection and surface radiation in tilted square and shallow enclosures," International Journal of Thermal Sciences, vol. 60, pp. 70-84, 2012.

[17] S. G. Martyushev and M. A. Sheremet, "Conjugate natural convection combined with surface thermal radiation in an air filled cavity with internal heat source," International Journal of Thermal Sciences, vol. 76, pp. 51-67, 2014.

[18] S.-Y. Wu, J.-Y. Guan, L. Xiao, Z.-G. Shen, and L.-H. Xu, "Experimental investigation on heat loss of a fully open cylindrical cavity with different boundary conditions," Experimental Thermal and Fluid Science, vol. 45, pp. 92-101, 2013.

[19] R. E. Hogan, R. B. Diver, and W. B. Stine, "Comparison of a cavity solar receiver numerical model and experimental data," Journal of Solar Energy Engineering, vol. 112, no. 3, pp. 183-190, 1990.

[20] X. Li, W. Kong, Z.-F. Wang, C. Chang, and F. Bai, “Thermal model and thermodynamic performance of molten salt cavity receiver," Renewable Energy, vol. 35, no. 5, pp. 981-988, 2010.

[21] Q.-Q. Zhang, X. Li, Z.-F. Wang, C. Chang, and H. Liu, "Experimental and theoretical analysis of a dynamic test method for molten salt cavity receiver," Renewable Energy, vol. 50, pp. 214221, 2013.

[22] A. F. Baker, S. E. Faas, L. G. Radosevich, and A. C. Skinrood, "U.S.-Spain evaluation of the Solar One and CESA-1 receiver and storage system," Sandia National Laboratories SAND88$8262,1989$.

[23] J. B. Fang, J. J. Wei, X. W. Dong, and Y. S. Wang, “Thermal performance simulation of a solar cavity receiver under windy conditions," Solar Energy, vol. 85, no. 1, pp. 126-138, 2011.

[24] J. B. Fang, N. Tu, and J. J. Wei, "Numerical investigation of startup performance of a solar cavity receiver," Renewable Energy, vol. 53, pp. 35-42, 2013.

[25] Q. Yu, Z. Wang, and E. Xu, "Simulation and analysis of the central cavity receiver's performance of solar thermal power tower plant," Solar Energy, vol. 86, no. 1, pp. 164-174, 2012.

[26] Q. Yu, Z. Wang, E. Xu, X. Li, and M. Guo, "Modeling and dynamic simulation of the collector and receiver system of 1 MWe DAHAN solar thermal power tower plant," Renewable Energy, vol. 43, pp. 18-29, 2012.

[27] M. J. Montes, A. Rovira, J. M. Martínez-Val, and A. Ramos, "Proposal of a fluid flow layout to improve the heat transfer in the active absorber surface of solar central cavity receivers," Applied Thermal Engineering, vol. 35, no. 1, pp. 220-232, 2012.

[28] S. M. Yang and W. Q. Tao, Heat Transfer, Higher Education Press, Beijing, China, 2006.

[29] P. Kesselring and C. S. Selvage, The IEA/SSPS Solar Thermal Power Plants: Facts and Figures, Final Report of the International Test and Evaluation Team (ITET), Springer, New York, NY, USA, 1986.

[30] S. G. Kandlikar, "A general correlation for saturated two-phase flow boiling heat transfer inside horizontal and vertical tubes," Journal of Heat Transfer, vol. 112, no. 1, pp. 219-228, 1990.

[31] Y. Y. Hsu, "On the size range of active nucleation cavities on a heating surface," Journal of Heat Transfer, vol. 84, no. 3, pp. 207216, 1962.

[32] O. G. Sutton, "Note on variation of the wind with height," Quarterly Journal of the Royal Meteorological Society, vol. 58, no. 243, pp. 74-76, 1932.

[33] R.-T. Wang and X.-D. Wei, "Shadow of heliostat fleld in the solar tower power plant," Acta Photonica Sinica, vol. 38, no. 9, pp. 2414-2418, 2009. 

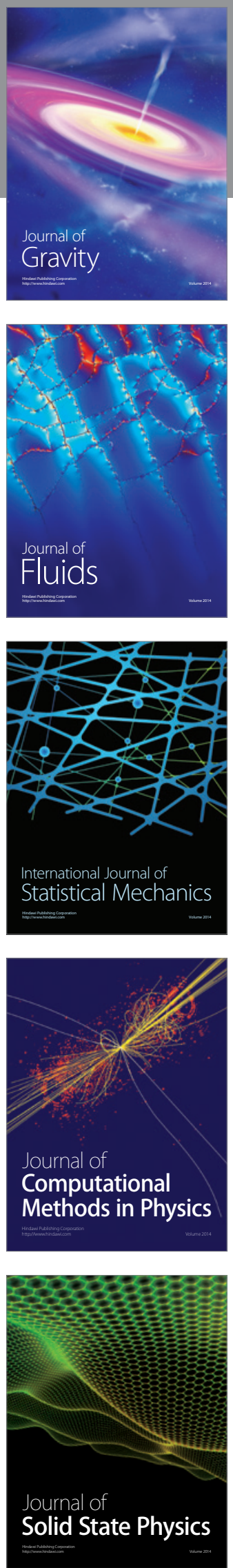

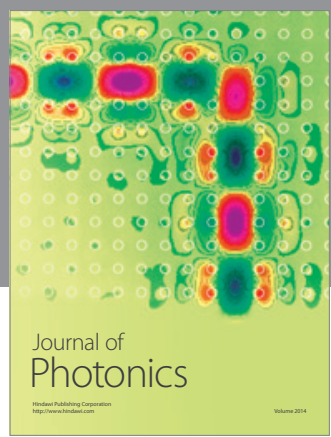

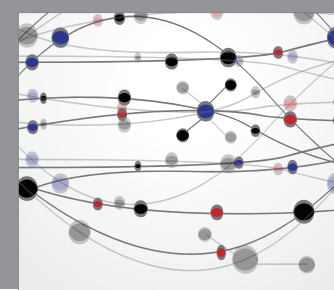

The Scientific World Journal

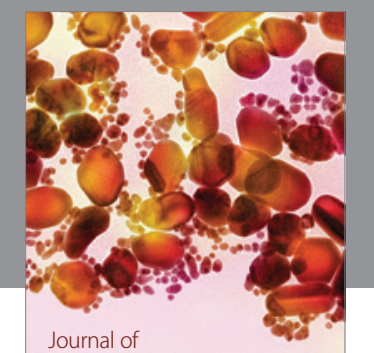

Soft Matter
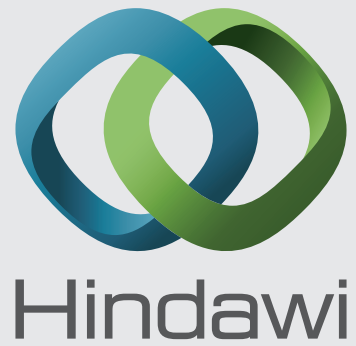

Submit your manuscripts at

http://www.hindawi.com
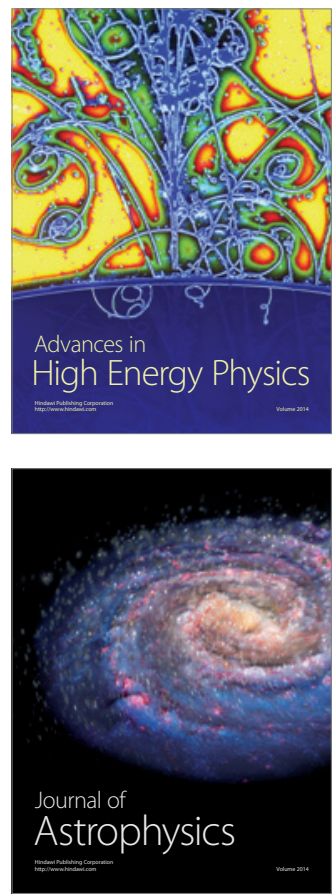
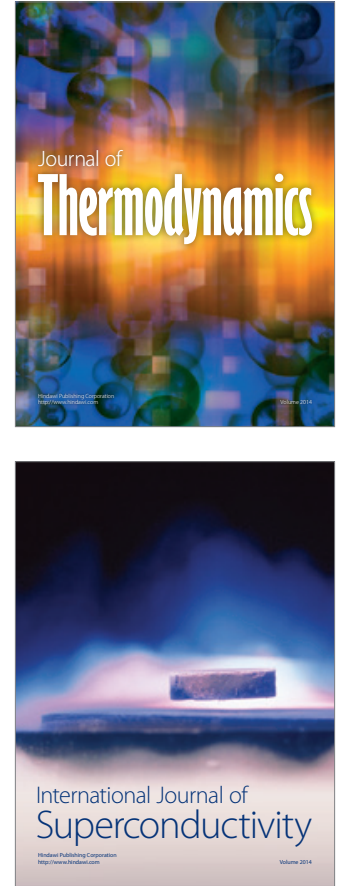
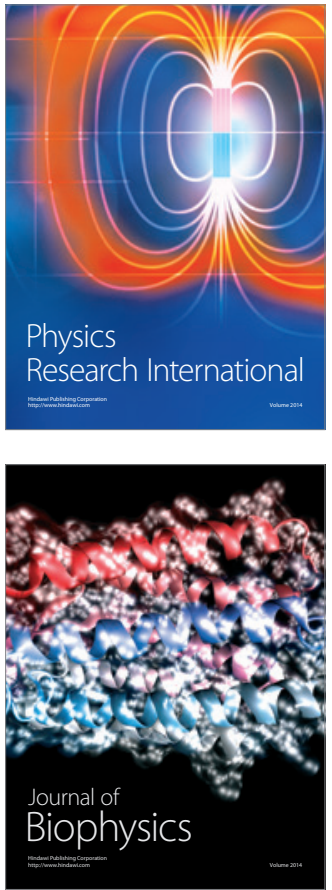
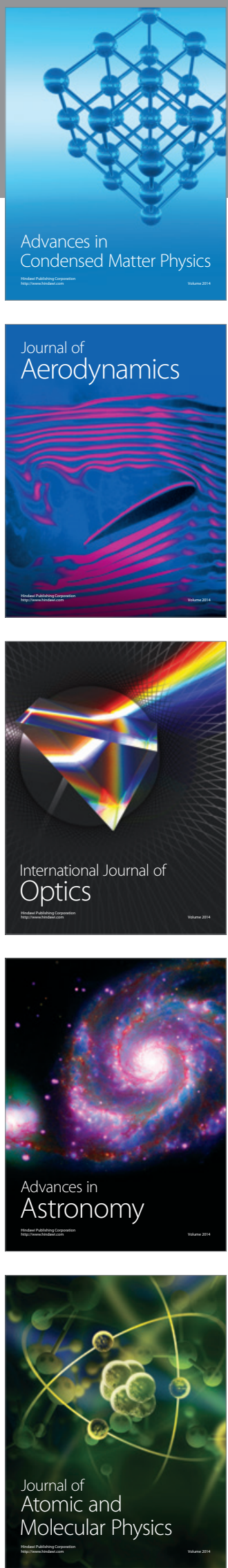